\title{
Linear interictal pain in Epicrania Fugax
}

\author{
Juan A Pareja ${ }^{*}$ and Pablo Bandrés
}

\begin{abstract}
Epicrania Fugax is a paroxysmal, short-lasting, head pain moving across one hemicranium, describing a linear or zag trajectory, starting and ending in territories of different nerves. Between attacks, patients are usually free of symptoms. We describe an Epicrania Fugax patient complaining of interictal pain. The interictal pain was line-shaped and extended across the usual starting and ending points of the typical Epicrania Fugax paroxysms. Although rarely encountered, persistent linear pain may be a feature of Epicrania Fugax.
\end{abstract}

\section{Correspondence/Findings}

Epicrania Fugax is a paroxysmal, short-lasting (1-10 s), head pain moving across one hemicranium, describing a linear or zag trajectory, starting and ending in territories of different nerves [1,2]. At the end of the attacks, ipsilateral autonomic signs such as lacrimation, conjunctival injection or rhinorrhoea may occur. Between attacks, patients are usually free of symptoms. However, we have recently encountered an Epicrania Fugax patient complaining of interictal pain. This finding was not a surprise as interictal pain may be a feature of paroxysmal headaches [3] and trigeminal neuralgia [4].

A 39-year-old female patient complained of one-daylasting episodes of linear-shaped pain in her right hemicranium. In the past few months she had been suffering from paroxysms of severe pain lasting 5-10 seconds, starting in the posterior parietal area of the right hemicranium and rapidly moving with a lineal trajectory to the internal canthus of the ipsilateral eye. As a rule, once the pain reached the eye, lacrimation ensued. The frequency ranged from 1 to 3 paroxysms daily, in the symptomatic days (2-3/week). In between attacks, the patient felt a continuous, moderate pain, confined to the territory where the motion was perceived. The patient clearly delineated the painful lineal area in her head and could finely draw it, thus giving a definite impression of the localization of such an interictal pain.

Wang Y et al. [5] described headaches with pain episodes localized in a line-shaped area of one hemicranium. Topographically, this description parallels that of our patient. However, the patients of Wang Y et al. did not report moving paroxysms. More evidences are needed before we can decipher the nosologic position of linear headaches, but as far as Epicrania Fugax is concerned, its clinical features may rarely include a linear interictal pain that may even become the main complaint.

\section{Competing interests}

The authors declare that they have no competing interests.

\section{Authors' contributions}

JAP: made the clinical observation and wrote the manuscript. PB:

contributed to the final draft of the article. Both authors commented on the manuscript and approved the final version of the manuscript.

Received: 3 February 2015 Accepted: 26 February 2015

Published online: 19 March 2015

\section{References}

1. Pareja JA, Cuadrado ML, Fernández-de-las-Peñas C, Caminero AB, Nieto C, Sánchez C, Sols M, Porta-Etessam J (2008) Epicrania Fugax: an ultrabrief paroxysmal epicranial pain. Cephalalgia 15:257-263

2. Headache Classification Committee of the International Headache Society (2013) The international classification of headache disorders, 3rd edition (beta version). Cephalalgia 33:629-808

3. Marmura MJ, Young WB (2012) Interictal pain in primary headache syndromes. Curr Pain Headache Rep 16:170-174

4. Maarbjerg S, Gozalov A, Olesen J, Bendtsen L (2014) Trigeminal neuralgia: a prospective systematic study of clinical characteristics in 158 patients. Headache 54:1574-1582

5. Wang Y, Tian MM, Wang XH, Zhu XQ, Liu Y, Lu YN, Pan QQ (2014) Linear headache: a recurrent unilateral head pain circumscribed in a line-shaped area. J Headache Pain 26:15-45

\footnotetext{
* Correspondence: japareja.mad@quiron.es

Department of Neurology, University Hospital Fundación Alcorcón, Budapest 1, Madrid 28922, Alcorcón, Spain
}

\section{Springer}

(C) 2015 Pareja and Bandrés; licensee Springer. This is an Open Access article distributed under the terms of the Creative Commons Attribution License (http://creativecommons.org/licenses/by/4.0), which permits unrestricted use, distribution, and reproduction in any medium, provided the original work is properly credited. 